4th International Scientific Conference SEC-IASR 2019,

Galati, Romania, 7th - 8th June, 2019

\title{
Correlations between the Coordinating Capacities and the Technical Parameters at the Level of the Handball Teams (Junior III)
}

\author{
Madalina-Gabriela POSTELNICU, Ion MIHAILA \\ https://doi.org/10.18662/lumproc/sec-iasr2019/33
}

How to cite: Postelnicu, M.-G., \& Mihaila, I. (2020). Correlations between the Coordinating Capacities and the Technical Parameters at the Level of the Handball Teams (Junior III). In S. Marin \& P. Moisescu (vol. eds.), Lumen Proceedings: Vol. 12. 4th International Scientific Conference SEC-LASR 2019 (pp. 309-315). Iasi, Romania: LUMEN Publishing House. https://doi.org/10.18662/lumproc/sec-iasr2019/33 



\title{
Correlations between the Coordinating Capacities and the Technical Parameters at the Level of the Handball Teams (Junior III)
}

\author{
Madalina-Gabriela POSTELNICU ${ }^{1 *}$, Ion MIHAILA²
}

Abstract

\begin{abstract}
Nowadays, the characteristics of the modern handball game impose the part of the young practitioners the possession of a really rich motor-technical stock and the quickly adaptation to the encounter of unforeseen situations during the game in order to efficiently achieve the gaming tasks. The purpose of this study is to determinate the relationships between the coordinating capacities and the technical parameters of the handball players. In this regard, the research was carried out on a group of athletes aged between 13-14 years, within the Handball Sports Club-ART Galati. Athletes have been tested in terms of coordination skills and technical training. To evaluate the influence of the coordinating capabilities on the technique and vice versa, we chose the calculation of the Pearson correlation coefficient $r$. Based on the results obtained, $r$ has values between $30 \%$ and $89 \%$ in 20 calculated correlations, which proves the existence of a connection between the two variables. We can say that the development of coordination capacities at this age echelon is a priority factor in learning and strengthening the specific elements and techniques of handball. Thus, it is advisable to use various methodical procedures in the training process that lead to the development of this psychomotor quality. At the same time, in selecting the means of action for the development of coordination capacities, one has to take into account the particularities of the age, the level of training and the training period.
\end{abstract}

Keywords: handball; coordinating capacities; technical training; correlation coefficient; junior III.

\footnotetext{
${ }^{1}$ Secondary school no. 1 Tulucesti, Galati, Romania, postelnicumadalinagabriela@yahoo.ro

2 University of Pitesti, Pitesti, Romania, paulmihaila@yahoo.com
} 


\section{Introduction}

Considering the fact that the handball game in the last years registered a spectacular evolution, characterized by a diversity of game phases, it requires from the practitioners to master a significant number of technical elements and procedures. As part of the junior team training process, it is important for coaches to work towards the development of coordinating capacities, which are considered to be elementary in the practice of handball. At age 13-14, successful technical elements can be successfully acquired, which requires athletes to have good general and specific coordination.

\section{Problem Statement}

Sport is a phenomenon of the modern world, having as main task the development of the biological potential of man being considered as one of the most dynamic social activities, which motivates the specialists' interest to carry out constantly various analyzes and studies in order to detect his development tendencies [3], [8].

The specialized literature characterizes handball as a collective and dynamically game based on a series of natural movements such as running, throwing, jumping on the one hand and specific motor skills on the other, with a relatively simple technique, accessible to all age groups [4], [5].

Since its appearance until now, handball is constantly evolving, due to the permanent concerns of specialists regarding the development and realization of a game and training concept.

This spectacular evolution has prompted a series of changes that impose from those who are involved in the training of handball teams to pay special attention to the particularities of modern handball and to be in touch with everything new.

In order to practice the handball game, a number of driving actions are required made by athletes according the level of knowledge of gamespecific driving skills and the level of development of motor skills [1].

Athletes must possess a number of driving qualities to successfully complete all handball specific moves.

In the literature four basic motor skills are mentioned: speed, deftness, force and resistance.

The deftness is considered to be "the finest and most complex quality in performance sports. Without it, all other qualities can not be 
capitalized, as a man full of qualities, but without a solid culture can not make his personality" [7].

As a complex motorship, predominantly psycho-motric, with many aspects and multiple interferences with the other qualities and motor skills, a number of authors gave up the generic name of deftness, this being called coordination or coordination capabilities [3], [9].

Coordinating capacities are defined as a „complex of predominantly psycho-motric qualities that imply the ability to learn quickly new movements, adapting quickly and efficiently to the varying conditions specific to the different types of activities by restructuring the existing motric fund" [2].

In Hahn E.'s view, coordination is ,accomplished by the simultaneous action of the central nervous system and skeletal muscles in order to carry out a voluntary movement in such a way that there is a harmonious chaining between the different components of this movement" [6].

An important aspect of the quality of coordination functions is that it directly influences the speed and quality in learning the techniques specific to the various sports disciplines [6].

Some athletes are born with certain indices of these coordinating capacities, while others acquire them in the training process.

\section{Research Questions/Aims of the research}

The purpose of this study is to determine the relationships between the coordinating capacities and the technical parameters at the level of handball teams juniors III female.

The research objectives are:

- Selection and application of technical tests that can objectively measure the level of technical preparation of the sample of work under research.

- Evaluating the level of development of coordinating capacities by applying tests with a high degree of applicability at puberty age.

- Determining the existing links between the coordinating capacities and the technical parameters. 


\section{Research Methods}

The sample of the research consisted of 16 female athletes, aged 12 to 14 years, what make up the juniors team III of the ClubuluiSportiv Handball-ART Galati. In order to achieve the objectives we used a whole battery of tests to test athletes both from a technical point of view and from the point of view of the level of development of coordination capabilities. To mention that during the whole activity, the health of the athletes was good.

Tests used in research:

- technical tests: $30 \mathrm{~m}$ dribbling through the cones, throwing the handball ball at distance,throwing the ball in the wall and repeating it (variant 1), throwing the ball at a fixed point(2nd variant), slalom in the dribbling, technical test for the players field, technical test for goalkeepers.

- tests on coordinating capacities: balance on the bench, returns to the gym bench (2nd variant), sprint in the proposed rhythm , the square test, running to the balls, driving the basketball ball with skillful hand, tapping-test (variant 1).

The methods used during this study were: the bibliographic study method, the observation method, the experimental study method, the test method, the statistical-mathematical methodology.

The correlations between the coordinating capacities and the technical parameters were determined by applying the Pearson correlation coefficient $r$.

\section{Findings}

The sportives were tested from the technical point of view and from the point of view of the development of the coordinative capacities, after which Ianalyzed the obtained values (table no.1, table no.2). 
Madalina-Gabriela POSTELNICU \& ... | Lumen Proceedings 12 | SEC-IASR 2019

Table 1. The results obtained by team C.S. HANDBALL-ART (juniors III) to technical tests

\begin{tabular}{|c|c|c|c|}
\hline Technical testing & $\overline{\boldsymbol{X}}$ & $\mathbf{S}$ & $\mathrm{CV}_{\mathrm{V}}$ \\
\hline $\begin{array}{l}30 \text { mdribbling through the } \\
\text { cones(seconds) }\end{array}$ & 7,87 & 1,859 & $23,63 \%$ \\
\hline $\begin{array}{l}\text { Throwing the handball ball at distance } \\
\text { (meters) }\end{array}$ & 26,28 & 3,803 & $14,47 \%$ \\
\hline $\begin{array}{l}\text { Throwing the ball in the wall and } \\
\text { repeating it (variant } 1 \text { ) } \\
\text { (number of executions/minutes) }\end{array}$ & 38,25 & 2,620 & $6,85 \%$ \\
\hline $\begin{array}{l}\text { Throwing the ball at a fixed point } \\
\text { (2nd variant) } \\
\text { (number of executions/minutes) }\end{array}$ & 16,19 & 1,276 & $7,89 \%$ \\
\hline Slalom in the dribbling (seconds) & 15,19 & 1,859 & $12,24 \%$ \\
\hline $\begin{array}{l}\text { Technical test for the players field } \\
\text { (seconds) }\end{array}$ & 48,59 & 19,405 & $39,93 \%$ \\
\hline $\begin{array}{l}\text { Technical test for goalkeepers } \\
\text { (seconds) }\end{array}$ & 38,50 & 144,062 & $\begin{array}{c}374,19 \\
\%\end{array}$ \\
\hline $\bar{X}$-arithmetic mean S-standard deve & (n) & fur vi & \\
\hline
\end{tabular}

Table 2. The results obtained by team C.S. HANDBAL-ART (juniors III) in tests on the level of coordination skills development

\begin{tabular}{lccc}
\hline \multicolumn{1}{c}{ Tests on coordinating capacities } & $\overline{\boldsymbol{X}}$ & $\mathbf{S}$ & $\mathbf{C}_{\mathbf{v}}$ \\
\hline Balance on the bench(seconds) & 15,40 & 1,859 & $12,07 \%$ \\
Returns to the gym bench (2nd variant) & 8,75 & 1,880 & $21,48 \%$ \\
(number of executions/minutes) & & & \\
Sprint in the proposed rhythm (seconds) & 0,88 & 0,310 & $35,21 \%$ \\
The square test(seconds) & 11,84 & 1,276 & $10,78 \%$ \\
Running to the balls(seconds) & 52,39 & 1,859 & $3,55 \%$ \\
Driving the basketball ball with skillful hand & 9,28 & 0,712 & $7,68 \%$ \\
(seconds) & & & \\
Tapping-test (variant 1)(points) & 223,56 & 18,191 & $8,14 \%$ \\
\multicolumn{2}{c}{-arithmetic mean S-standard deviation $\mathrm{C}_{\mathrm{V}}$-coefficient of variability } & \\
\hline
\end{tabular}


Madalina-Gabriela POSTELNICU \& ... | Lumen Proceedings 12 | SEC-IASR 201

Table 3. Correlations between coordinating capacities and technical parameters

\begin{tabular}{cccccccc}
\hline & DAP & TBD & TBTR & TBFT & SD & TJC & TJP \\
\hline BBG & $\mathbf{0 . 8 9}$ & -0.33 & -0.32 & -0.47 & $\mathbf{0 . 6 8}$ & $\mathbf{0 . 7 6}$ & -1 \\
TGB & -0.45 & 0.01 & 0 & 0.02 & -0.50 & -0.54 & $\mathbf{1}$ \\
SGR & $\mathbf{0 . 6 4}$ & 0.17 & -0.26 & -0.17 & 0.58 & $\mathbf{0 . 6 0}$ & -1 \\
TST & 0.22 & $\mathbf{0 . 3 7}$ & 0.10 & -0.28 & $\mathbf{0 . 3 5}$ & $\mathbf{0 . 4 3}$ & $\mathbf{1}$ \\
RTB & $\mathbf{0 . 5 0}$ & 0.10 & 0.04 & -0.22 & $\mathbf{0 . 5 8}$ & $\mathbf{0 . 6 6}$ & -1 \\
LB & $\mathbf{0 . 7 2}$ & -0.29 & -0.37 & -0.66 & $\mathbf{0 . 6 1}$ & $\mathbf{0 . 6 7}$ & $\mathbf{1}$ \\
TAPPING & -0.26 & $\mathbf{0 . 6 2}$ & $\mathbf{0 . 3 0}$ & $\mathbf{0 . 3 9}$ & -0.47 & -0.13 & $\mathbf{1}$ \\
$\mathbf{1}$ & & & & & & &
\end{tabular}

BBG-Balance on the bench;TGB-Returns to the gym bench (2nd variant); SGR-Sprint in the proposed rhythm; TST-The square test; RTB-Running to the balls; LB-Driving the basketballball with skillful hand;TAPPING 1Tapping-test (variant 1);DAP-30 $\mathrm{m}$ dribbling through the cones;TBD-Throwing the handball ball at distance;TBTR 1-Throwing the ball in the wall and repeating it (variant 1);TBFT 2-Throwing the ball at a fixed point (2nd variant); SDSlalom in the dribbling;TJC-Technical test for the players field;TJP-Technical test for goalkeepers.

\section{Discussions}

When analyzing the correlations between the coordinating capacities and the technical parameters (Table 3), we can observe that $r$ has positive values in 21 calculated correlations, which proves the existence of a link between the two variables.In the training process, when it comes to the formation of new motor skills, these have to rely on what has been learned before, thus intervening with the transfer phenomenon.For example, the correct learning of the basic mechanism of the technical process of throwing to the gate with crossing step will have positive influences on throwing at the gate of the bounce preceded of crossing step. 


\section{Conclusions}

We can say that the development of coordination capacities at this age echelon is a priority factor in learning and strengthening the specific elements and techniques of handball. Thus, it is advisable to use various methodical procedures in the training process that lead to the development of this psychomotor quality. At the same time, in selecting the means of action for the development of coordination capacities, one has to take into account the particularities of the age, the level of training and the training period.In order to achieve sports performance, it is very important to work constantly to develop coordinating skills regardless of the age of the subjects.

\section{References}

[1] Bastiurea E. Handball-Concepts, principles and ways to improve training. Galati-Academica; 2007. 81 p.

[2] Dragnea A, Bota I. Theory of driving activities. Bucharest: Didactic and Pedagogical Publishing House; 1999. 243 p.

[3] Dragnea AC, Mate-Teodorescu S. The theory of sports. Bucharest: FEST; 2002. $347 \mathrm{p}$.

[4] Ghermanescu-Kunst I. Handball in 7. Bucharest: Publishing House of Physical Culture and Sports; 1966.7 p.

[5] Ghermanescu-Kunst I. et all. The handball theory and methodology. Bucharest: Didactic and Pedagogical Publishing House; 1983. 5 p.

[6] Hahn E. Sports training for children. Bucharest: CCPS; 1996. 95 p.

[7] Ludu V. The skill and method of its development. Bucharest: National Council for Physical Education and Sport Publishing House; 1969. 9 p.

[8] Mihaila I. Handball-Optimizing specific physical training in junior teams. Craiova: EUC; 2006. 13 p.

[9] Mitra Gh, Mogos Al. Developing motor skills. Bucharest: Sport-Turism Publishing House; 1977. 186 p. 